\title{
SÍNDROME INFLAMATÓRIA MULTISSISTÊMICA PEDIÁTRICA (SIM-P) TEMPORALMENTE ASSOCIADA À COVID-19
}

\author{
PEDIATRIC MULTISYSTEM INFLAMMATORY SYNDROME (MISC-C) TEMPORALLY \\ ASSOCIATED WITH COVID-19
}

\begin{abstract}
Eliane Cristina Casimiro Alves Dias'; Carolina Dias Azevedo², Gabriel Fernandes Maciel da Silva², Gabriela Barbosa e Silva², Ligia de Lima e Silva²

'Professora de Pediatria da Faculdade de Medicina de Campos - FMC, Campos dos Goytacazes - RJ.

${ }^{2}$ Discentes do Curso de Graduação em Medicina da Faculdade de Medicina de Campos - FMC, Campos dos

Goytacazes - RJ.
\end{abstract}

\section{RESUMO}

Introdução: A pandemia pela COVID-19 é menos incidente na população pediátrica quando comparada à adulta, sendo apenas $2 \%$ dos casos abaixo dos 20 anos. Recentemente, a infecção pelo SARS-CoV-2 em crianças e adolescentes está sendo associada à Síndrome Inflamatória Multissistêmica Pediátrica (SIM-P), doença de Kawasaki-like. Objetivo: Relatar a ocorrência de uma das apresentações clínicas da COVID-19 na infância, a SIM-P, ressaltando suas manifestações clínicas, laboratoriais e manejo clínico. Descrição do Caso: Feminina, 9 anos, admitida com dor abdominal e febre há três dias, além de contato domiciliar com infectado pelo SARS-CoV-2 nos últimos 30 dias. Encontrava-se febril, com sobrepeso e abdome distendido em região epigástrica. Evoluiu com máculas eritematosas em dorso, edema e fissuras labiais, artralgia, mialgia, vômitos, hemorragia subconjuntival, língua em framboesa, sudorese, taquidispneia e tonteira. Exames com hemoglobina de $11,4 \mathrm{~g} / \mathrm{dL}, 4.200$ leucócitos, proteína C reativa de $18 \mathrm{mg} / \mathrm{dL}$, tomografia computadorizada de tórax com pequenos linfonodos no espaço pré-vascular. Recebeu $1,5 \mathrm{mg} / \mathrm{kg} / \mathrm{dia}$ de Imunoglobulina Humana com rápida regressão e melhora clínica. Discussão: A SIM-P ocorre em dias a semanas após uma infecção aguda pelo SARS-CoV-2. Suas manifestações clínicas se assemelham à doença de Kawasaki. Na maior parte dos casos, o teste de SARSCoV-2 PCR é positivo demonstrando infecção recente, ocorrendo em crianças mais velhas, com marcadores inflamatórios exuberantes e disfunção de múltiplos órgãos. Conclusão: Estudos epidemiológicos e clínicos adicionais são necessários para melhor compreensão da fisiopatologia dessa nova síndrome. Embora rara, é necessário alertar a comunidade pediátrica, para ampliar e otimizar o reconhecimento com tratamento precoce da mesma.

PALAVRAS-CHAVE

COVID-19; Doença de Kawasaki; Síndrome Inflamatória; SARS-CoV-2; Pediatria.

\section{ABSTRACT}

Introduction: The COVID-19 pandemic is less prevalent in the pediatric population when compared to the adult, with only $2 \%$ of cases under 20 years old. Recently, SARSCoV-2 infection in children and adolescents is being associated with Pediatric Multisystemic Inflammatory Syndrome (SIM-P), Kawasaki-like disease. Objective: To report the occurrence of one of the clinical presentations of COVID-19 in childhood, SIM-P, highlighting its clinical, laboratory and clinical management. Case Description: Female, 9 years old, admitted with abdominal pain and fever for three days, in addition to home contact with those infected with SARS-CoV-2 in the last 30 days. She was feverish, with overweight and distended abdomen in the epigastric region. It evolved with erythematous macules on the back, edema and cleft lip, arthralgia, myalgia, vomiting, subconjunctival hemorrhage, raspberry tongue, sweating, tachydyspnea and dizziness. Tests with hemoglobin of $11.4 \mathrm{~g} / \mathrm{dL}, 4,200$ leukocytes, C-reactive protein of $18 \mathrm{mg} / \mathrm{dL}$, computed tomography of the chest with small lymph nodes in the pre-vascular space. He received $1.5 \mathrm{mg} / \mathrm{kg} /$ day of Human Immunoglobulin with rapid regression and clinical improvement. Discussion: SIM-P occurs within days to weeks after an acute SARS-CoV-2 infection. Its clinical manifestations resemble Kawasaki's disease. In most cases, the SARSCoV-2 PCR test is positive, showing recent infection, occurring in older children, with exuberant inflammatory markers and multiple organ dysfunction. Conclusion: Additional epidemiological and clinical studies are needed to better understand the pathophysiology of this new syndrome. Although rare, it is necessary to alert the pediatric community to expand and optimize recognition with early treatment.

\section{KEYORDS}

COVID-19; Kawasaki Disease; Inflammatory Syndrome; SARS-CoV-2; Pediatrics. 


\section{INTRODUÇÃO}

A pandemia da COVID-19 (Coronavirus Disease-2019) que afetou milhões de pessoas ao redor do mundo desde Novembro de 2019, manifesta uma incidência relativamente baixa de infecções agudas na população pediátrica quando em comparação à adulta, com apenas $2 \%$ dos casos descritos abaixo dos 20 anos de idade. ${ }^{1}$ Apresentando-se nesse grupo de forma branda, com sintomas respiratórios leves, sem necessidade de hospitalização ou cuidados intensivos. Entretanto, tem sido relatado recentemente na comunidade médica uma nova síndrome clínica grave associada à infecção pelo Coronavírus ${ }^{2}$ da Síndrome Respiratória Aguda Grave (SARS-CoV-2) em crianças e adolescentes, a denominada Síndrome Inflamatória Multissistêmica Pediátrica $(\mathrm{SIM}-\mathrm{P}) .^{2}$ Esta se caracterizada por febre persistente, marcadores laboratoriais de inflamação, disfunção de múltiplos órgãos, principalmente com dor abdominal e diarreia, além de características sugestivas da síndrome de Kawasaki. ${ }^{3}$

A doença de Kawasaki (DK) é uma vasculite sistêmica aguda primária, de etiologia ainda não completamente esclarecida, que afeta preferencialmente vasos de médio calibre. Nos países desenvolvidos, corresponde à principal causa de doença cardíaca adquirida na infância. Seu diagnóstico é essencialmente clínico, na vigência da manifestação clássica: febre alta e contínua por pelo menos 5 dias associada à, no mínimo, 4 dos 5 critérios determinados pela American Heart Association (AHA): (1) Alterações de lábios e cavidade oral, (2) hiperemia conjuntival, (3) alterações de extremidades, (4) exantema polimorfo e (5) linfadenopatia cervical $\geq 1,5 \mathrm{~cm}$, geralmente unilateral. ${ }^{1},{ }^{4}$

Deve-se considerar DK incompleta na vigência de menos de quatro critérios clínicos ou ecocardiograma demonstrando aneurisma coronariano. Nesses casos, o diagnóstico pode ser determinado na presença de três ou mais dos seguintes achados laboratoriais: $\mathrm{PCR}>3 \mathrm{mg} / \mathrm{dL}$; VHS $>40 \mathrm{~mm} / \mathrm{h}$; anemia para a idade; plaquetas > $450.000 / \mathrm{mm}^{3}$ (após 7 dias de doença); leucocitose $\left(>15.000 / \mathrm{mm}^{3}\right)$; piúria estéril; TGP $>50 \mathrm{U} / \mathrm{L}$; albumina $<3 \mathrm{~g} / \mathrm{dL}$; hiponatremia; e ecocardiograma mostrando dimensões coronarianas $>2,5$, por meio doZ-escore. ${ }^{4}$

Nesse contexto, critérios estabelecidos pelo Centers for Disease Control (CDC) e pela Organização Mundial de Saúde (OMS) podem orientar os médicos pediatras a diagnosticar essa nova condição em associação com a alta prevalência local de COVID-19 (Figura 1). ${ }^{4}$

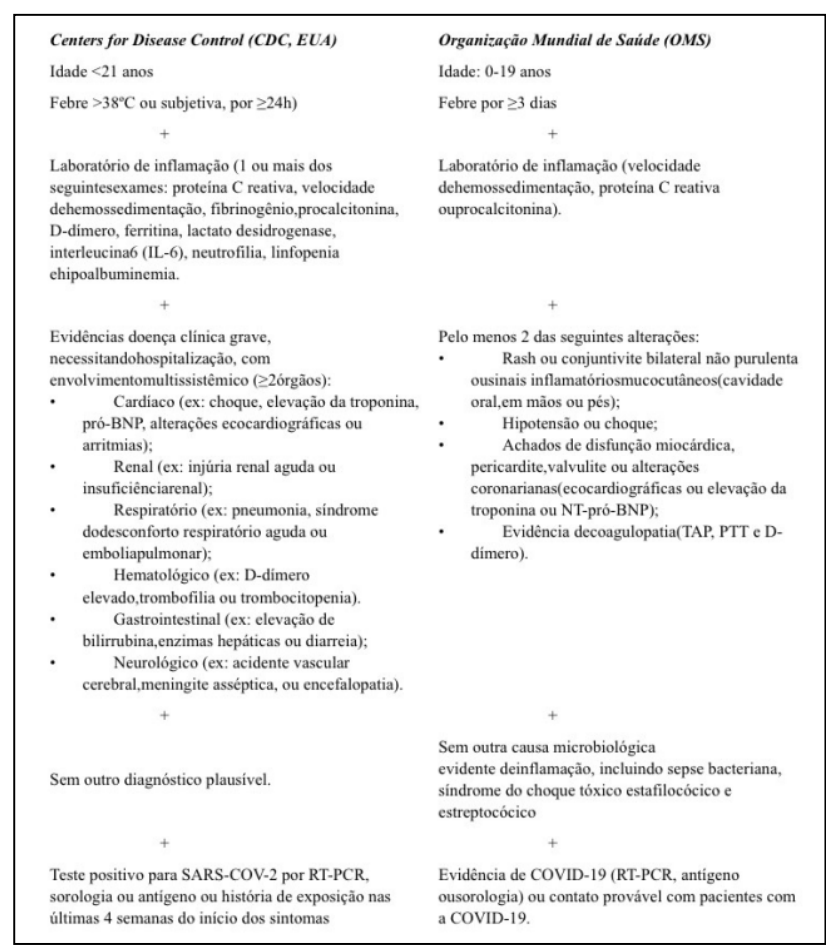

Figura 1 - Fonte: CAMPOS LR, 2020

\section{OBJETIVO}

Este trabalho objetiva relatar a ocorrência de uma das apresentações clínicas da COVID-19 na infância, a Síndrome Inflamatória Multissistêmica Pediátrica, ressaltando suas manifestações clínicas, achados laboratoriais e manejo clínico.

\section{DESCRIÇÃO DO CASO}

Paciente do sexo feminino, nove anos de idade, parda, natural de Campos dos Goytacazes. Foi admitida na clínica pediátrica de referência da Secretaria Municipal de Saúde (SMS) para COVID-19 com quadro de dor abdominal e febre alta persistente há três dias. Negava episódios eméticos, diarreia ou qualquer sintomatologia respiratória. A responsável pela paciente referiu que a mesma teve contato domiciliar com um indivíduo infectado pelo SARSCoV-2 nos 30 dias precedentes ao atendimento médico.

Ao exame físico, encontrava-se febril $\left(38,7^{\circ} \mathrm{C}\right)$, ativa, eupneica, hidratada, acianótica, anictérica, hipocorada $(+/ 4+)$, com sobrepeso, sem alterações do estado de consciência e nuca livre. Não apresentava alterações ao exame do aparelho respiratório ou cardiovascular. Abdome apresentavase um pouco distendido em região epigástrica e sem 
sinais de irritação peritoneal. Foram solicitados exames laboratoriais que evidenciaram discreta anemia, com hemoglobina de $11,4 \mathrm{~g} / \mathrm{dL}, 4.200$ leucócitos, $17 \%$ de bastões, $66 \%$ de segmentados, 184.000 plaquetas e proteína C reativa de $18 \mathrm{mg} / \mathrm{dL}$. A radiografia de tórax demonstrou alterações sugestivas de broncopneumonia e foi, então, prescrito Ceftriaxone e indicada a internação hospitalar (IH).

No dia 1 (D1) de IH, em associação ao quadro clínico já estabelecido, novas alterações se instalaram. A paciente passou a apresentar pequenas máculas eritematosas, principalmente em dorso, edema e fissuras labiais, artralgia e mialgia. A reação em cadeia da polimerase em tempo real (RT$\mathrm{PCR}$ ) se mostrou reagente para SARS-CoV- 2 , sendo então instituído tratamento com Azitromicina e Olseltamivir. A Tomografia Computadorizada (TC) de tórax evidenciou pequenos linfonodos no espaço pré-vascular e volume cardíaco preservado, enquanto a TC de abdome e pelve mostrou ausência de linfonodomegalias retroperitoneais e pequena quantidade de líquido livre no fundo de saco posterior. As sorologias para vírus Epstein-Barr, dengue, zika, chikungunya, toxoplasmose e citomegalovirus não revelaram infecção recente. $A$ Ecocardiografia Bidimensional com Doppler colorido não demonstrou alterações.

Nas 48 horas subsequentes, a paciente evoluiu com episódios de vômitos, persistência da dor abdominal e da febre alta, além de hemorragia subconjuntival, "língua em framboesa", sudorese, taquidispneia e tonteira. Não apresentou sinais de comprometimento respiratório, tendo feito uso de oxigênio suplementar por pouco tempo. Foram solicitados novos exames laboratoriais.

Com base no quadro clínico apresentado e nos critérios estabelecidos pelo CDC e pela OMS, foi definido o diagnóstico da SIM-P temporalmente associada à COVID-19. Dessa forma, no nono dia dos sintomas, a paciente recebeu $1,5 \mathrm{mg} / \mathrm{kg} / \mathrm{dia}$ de Imunoglobulina Humana, o que promoveu a regressão das manifestações clínicas e melhora do estado geral em menos de 24 horas. Ao completar o esquema antimicrobiano, recebeu alta hospitalar para acompanhamento ambulatorial, em excelentes condições clínicas e com a normalização das provas inflamatórias.

\section{DISCUSSÃO}

A Síndrome Inflamatória Multissistêmica Pediátrica ocorre em dias a semanas após uma infecção aguda pelo SARS-CoV-2. Suas manifestações clínicas se assemelham à doença de Kawasaki, Kawasaki incompleto, à síndrome de choque associada à síndrome de Kawasaki e à síndrome de ativação macrofágica. Na maior parte dos casos, ocorre em crianças mais velhas, escolares e adolescentes, apresentando marcadores inflamatórios exuberantes e importante elevação dos marcadores de lesão cardíaca. ${ }^{6}$,

Faz-se necessário excluir infecções bacterianas, choque tóxico estreptocócico ou estafilocócico e outras causas virais compatíveis com agentes etiológicos de miocardite. ${ }^{7}$

$\mathrm{O}$ teste de SARS-CoV-2 PCR pode ser positivo ou negativo. Contudo, a maioria das crianças identificadas com SIM-P apresentaram testes de anticorpos positivos para COVID-19, demonstrando infecção recente. ${ }^{5}, 7$

Relatos semelhantes na literatura descrevem, também, população de pacientes composta por crianças previamente saudáveis, apresentando febre alta persistente, manifestações gastrointestinais intensas, conjuntivite não purulenta, exantema polimórfico, edema de mãos e pés, mucosite oral, linfadenopatia generalizada (incluindo mediastinal e intra-abdominal), hepatoesplenomegalia, serosite, irritabilidade, cefaleia, e alteração de nível de consciência. Alguns casos evoluíram com choque (hipotensão arterial, taquicardia e distúrbio de perfusão). Além disso, muitos pacientes estavam com sobrepeso ou obesos. Já os sintomas respiratórios costumam ser menos presentes e relevantes, podendo ser decorrentes da descompensação hemodinâmica. ${ }^{5}, 6$

Embora a SIM-P tenha características em comum com a doença de Kawasaki, diferenças relevantes incluem a intensidade dos sintomas gastrointestinais, a faixa etária mais elevada, predominando na média de 8,6 anos enquanto em pacientes com doença de Kawasaki 2,5 anos, e as medidas acentuadamente mais elevadas de marcadores inflamatórios, com maior incidência de choque e/ou função cardíaca prejudicada. ${ }^{3}$

Ainda não há um teste diagnóstico específico, sendo este baseado em um conjunto de fatores clínicos, laboratoriais e epidemiológicos. Um grupo de pacientes pode atender totalmente ou parcialmente os critérios para doença de Kawasaki, outros podem atender critérios para a síndrome do choque tóxico. Nesse sentido, diante de um quadro sugestivo de SIM-P, deve-se fazer uma série de exames para investigar o acometimento 
multissistêmico como hemograma completo, marcadores de função renal e hepática, monitorização da atividade inflamatória e a possibilidade do estado de hipercoagulabilidade. ${ }^{3,5,6}$

Com a confirmação da suspeita inicial, e teste específico do RNA SARS-CoV-2ou sorologia positiva deve-se completar a avaliação com a solicitação de LDH, triglicerídeos, ferritina, CK, investigação de distúrbios de coagulação com a dosagem de TAP, PTT, D-dímero, fibrinogênio, marcadores de função miocárdica e exames para avaliar as manifestações cardiovasculares como eletrocardiograma, ecocardiograma e radiografia ou tomografia computadorizada de tórax. 5

Não existe um protocolo validado para o tratamento da SIM-P e cada serviço tem adotado condutas semelhantes, apesar de nem sempre iguais, considerando o quadro clínico de cada paciente e sua gravidade. Nos casos que se apresentam com critérios diagnósticos de Doença de
Kawasaki clássica, tem sido indicada a terapia usual com gamaglobulina endovenosa e ácido acetilsalicílico. ${ }^{5}, 6$

\section{CONCLUSÃO}

Apesar da COVID-19 ter uma incidência baixa e apresentação relativamente benigna na população pediátrica, nos últimos meses um número crescente de casos está sendo relatado em nível mundial de crianças acometidas pela SIM-P. Estudos epidemiológicos e clínicos adicionais são necessários para melhor compreensão da fisiopatologia dessa nova síndrome. Mesmo rara, afetando não mais que 1 em cada 1000 crianças expostas ao SARS-CoV-2, no atual cenário de pandemia é fundamental alertar a comunidade pediátrica, para ampliar e otimizar seu reconhecimento, possibilitando tratamento precoce da mesma.

\section{REFERÊNCIAS}

1. Jones VG, Mills M, Suarez D, et al. COVID-19 and Kawasaki disease: novel virus and novel case. Hosp Pediatr. 2020; 10:537-540.

2. Sampaio CA, Amorim ERS, Sampaio GBA, Bohrer WFVA, Vasconcelos CG, Oliveira IF, et al. RELATO DE CASO: SíNDROME INFLAMATÓRIA MULTISSISTÊMICA ASSOCIADA À INFECÇÃO PELO SARS-CoV-2 EM PEDIATRIA. Resid Pediatr. 202;0(0):

3. Capone CA, et al. Characteristics, Cardiac involvement, and Outcomes of Multisystem Inflammatory Disease of Childhood (MIS-C) Associated with SARS-CoV-2 Infection. The Journal of Pediatrics. 2020; 224: 141-145.

4.Rauf A., Vijayan A., John ST, Krishnan R., Latheef A . Multisystem inflamatório syndrome with features of atypical Kawasaki disease during COVID-19 pandemic. Indian J Pediatr 2020; pp. 2-4.

5. Campos LR, Cardoso TM, Martinez JCFF, Almeida RG, Silva RM, Fonseca AR, et al. Síndrome inflamatória multissistêmica pediátrica (MIS-C) temporariamente associada ao SARS-CoV-2. Resid Pediatr. 2020;10(2):1-6.

6.Castro REV. Síndrome inflamatória multissistêmica associada à Covid-19: veja como identificar para notificar. [publicação online]; 2020 [acesso em 30 agos 2020]. Disponível em: https://pebmed.com.br/sindrome-inflamatoria-multissistemicaassociada-a-covid-19-veja-como-identificar-para-notificar/amp/.

7. Berezin EN. SÍNDROME INFLAMATÓRIA MULTISSISTÊMICA PEDIÁTRICA (SÍNDROME ASSOCIADA TEMPORALMENTE AO COVID-19). [publicação online]; 2020 [acesso em 25 agos 2020]. Disponível em: https://www.spsp.org.br/2020/05/19/sindrome-inflamatoria-multissistemica-pediatrica/.

8. Riphagen S et al. Hyperinflammatory shock in children during COVID-19 pandemic. Lancet. 2020; 395:1607-8.

9. Verdoni $L$ et al. An outbreak of severe Kawasaki-like disease at the Italian epicentre of the SARS-CoV-2 epidemic: an observational cohort study. Lancet. 2020; 395:1771-8. 